\section{Re: Doctor-Patient Trust Among Chronic Pain Patients on Chronic Opioid Therapy after Opioid Risk Reduction Initiatives: A Survey}

To the Editor: I commend Dr. Karen Sherman and colleagues ${ }^{1}$ on their work on trust and the doctor-patient relationship in patients on chronic opioid therapy. There are, however, 2 issues that I would like addressed.

First, according to this article, when discussing the study population, "the remaining members received care from community doctors, about whom little information is available"; this point was not acknowledged as a limitation of the study. This is vital because the strongest predictors of trust in a doctor-patient relationship are the doctor's personality and behavior and patients' trust has been shown to be affected by doctors' interpersonal skills and style of communications. ${ }^{2-4}$ Could factors other than the opioid reduction initiatives have contributed to the differential trust level between the 2 groups?

Second, studies have shown that the type of health insurance affects patients' trust. Insurance plans with more choice of physician engender more trust. ${ }^{3,5,6}$ Given that all study participants were from Group Health Cooperative, a monolithic group, and there was no information given on the plan types, the generalizability of the results to the general population on chronic opioid therapy is not known.

Ayodeji Otufowora, MB, BS, MPH, CPH, Department of Epidemiology, College of Public Health and Health Professions and College of Medicine, University of Florida, Gainesville, FL The author has no conflicts of interest. The author is a Graduate school Dean's Scholar at the College of Public Health and Health Professions, University of Florida; and thankful to his research mentor, Dr. Linda Cottler, for her support.

\section{References}

1. Sherman, KJ, Walker RL, Saunders K, et al. Doctor-patient trust among chronic pain patients on chronic opioid therapy after opioid risk reduction initiatives: A Survey. J Am Board Fam Med 2018;31:578-87.

2. Hall MA, Dugan E, Zheng B, Mishra AK. Trust in physicians and medical institutions: What is it, can it be measured, and does it matter? Milbank Quarterly 2001;79: 613-39, v.

3. Hall MA, Zheng B, Dugan E, et al. Measuring patients' trust in their primary care providers. Med Care Res Rev 2002;59:293-318.

4. Thom DH, Ribisl KM, Stewart AL, Luke DA. Further validation and reliability testing of the Trust in Physician Scale. The Stanford Trust Study Physicians. Med Care 1999;37:510-7.

5. Kao AC, Green DC, Davis NA, Koplan JP, Cleary PD. Patients' trust in their physicians: Effects of choice, continuity, and payment method. J Gen Intern Med 1998;13:681-6.
6. Reschovsky JD, Kemper P, Tu H. Does type of health insurance affect health care use and assessments of care among the privately insured? Health Serv Res 2000;35(1 Pt 2):219-37.

doi: 10.3122/jabfm.2018.06.180199

The above letter was referred to the author of the article in question, who offers the following reply.

\section{Response: Re: Doctor-Patient Trust Among Chronic Pain Patients on Chronic Opioid Therapy after Opioid Risk Reduction Initiatives: A Survey}

To the Editor: We thank Dr. Otufowora for his interesting comments regarding our recent publication. ${ }^{1}$ First, we would like to point out that our article describes patients' trust in their physician in relation to managing opioid pain medications. It is not about their overall trust in their physician. As we noted in our article, ${ }^{2}$ management of chronic opioid therapy can be contentious and thus, it is possible that trust in this component of care could differ from other aspects of care. We are unaware of past research on this more specialized aspect of trust. For none of the physicians in the study did our research team have access to data on the doctor's interpersonal skills and style of communication. Nonetheless, it is hard to imagine that among the hundreds of primary care physicians who worked in the Group Health clinics, they would be systematically less skilled in interpersonal skills and communication than those community doctors who treated Group Health patients outside of those clinics, particularly when dealing with patients on chronic opioid therapy. This is especially true because our physicians were trained in the 4 habits model of clinical communication. $^{3}$

In addition, Dr Otufowora wondered whether our results would be generalizable to other types of health insurance, where presumably more choice of primary care physicians is available and trust in physicians could be higher? We have no data on this point, and indeed in our discussion section, encouraged further research on assessing the impact of opioid risk reduction initiatives in more diverse populations. Nonetheless, we think our findings are internally valid. We hope others are encouraged by our findings and this correspondence to undertake rigorous research on the patients' trust of physicians related to management of chronic opioid therapy.

Karen J. Sherman, PhD,

Michael Parchman, MD, MPH,

Evette J. Ludman, $\mathrm{PhD}$,

Michael Von Korff, ScD,

Kaiser Permanente Washington Health Research Institute, Seattle, WA 